\title{
EXPOSIÇÃO AO RUÍDO TECNOLÓGICO EM CTI: ESTRATÉGIAS COLETIVAS DE DEFESA DOS TRABALHADORES DE ENFERMAGEM
}

\author{
Exposure to noise technology in an intensive therapy center: \\ Collective strategies for the defense of workers in nursing
}

\section{La exposición al ruido tecnológico en un centro de terapia intensiva: Estrategias colectivas para la defensa de los trabajadores de enfermería}

\author{
Elias Barbosa de Oliveira
}

Márcia Tereza Luz Lisboa²

\section{RESUMO}

Estudo descritivo com abordagem qualitativa que objetivou identificar e analisar as estratégias coletivas de defesa elaboradas pelos trabalhadores de enfermagem diante do ruído tecnológico em Centro de Terapia Intensiva (CTI). Participaram do estudo 25 trabalhadores de enfermagem de um hospital universitário situado no município de Niterói (RJ) em 2004. Na coleta de dados, utilizou-se a entrevista semi-estruturada mediante um roteiro, e, no tratamento dos dados, a análise de conteúdo revelou os seguintes resultados: o ruído tecnológico gera incômodo e estresse. Para minimizar o sofrimento, os trabalhadores elaboram estratégias coletivas de defesa que os mantêm trabalhando. Conclui-se que as estratégias coletivas de defesa podem se caracterizar num fator que resulta em alienação, ocultando a compreensão real do contexto de trabalho. As ações preventivas e as mudanças a serem implementadas em relação ao ruído no CTI devem ser pautadas na participação dos trabalhadores e se reverterem em melhoria das condições de trabalho e bem-estar do grupo..

Palavras-chave: Enfermagem. Ruído. Saúde do Trabalhador. Saúde Mental.

\begin{abstract}
Descriptive study with qualitative approach that aimed to identify and analyze the defense collective strategies made by nursing staff in front of the technology noise in an Intensive Therapy Center (ITC). Twenty-five members of nursing staff of an intensive therapy center at a university hospital in Niteroi (RJ) participated in the study in 2004. For data collection, semi-structured interview was used and data were analyzed by means of content analysis that showed the follow results: the noise disturbs and stress. The workers make defenses collective strategies that allow them to keep on working without get sick. Although, the defense strategies can be characterized as a factor that results in alienation, hidden the real comprehension of work context workers Therefore, preventive actions and changes need to be implemented by the organization so that it could improve the work environment. Nursing staff members have an important role in helping the organization managers to set a healthier work environment.
\end{abstract}

\section{Resumen}

Estudio descriptivo con un enfoque cualitativo diseñado para analizar las estrategias colectivas de la defensa elaboradas pelos trabajadores de enfermería frente al sonido tecnológico en un centro de terapia intensiva. Veinticinco profesionales de la enfermería de un centro de terapia intensiva del Hospital Escuela en Niteroi (RJ) participaron en el estudio en 2004. Para la recolección de datos, una entrevista semi - estructurada fue utilizada. Los datos fueron analizados a través de una análisis de contenido que mostraran los resultados: los trabajadores elaboran estrategias colectivas de defensa que permiten trabajar. Estas estrategias muestran un conocimiento que permite a los individuos seguir trabajando, ya que crea formas adaptativa para contrarrestar el sonido en el ambiente de trabajo, buscando continuamente ser sujetos de la situación de trabajo. Adicionalmente, reportaron que el ruido los molestaba, estresaba y además conducía a errores y accidentes laborales. Por lo tanto, es necesario que la organización implemente acciones preventivas y cambios apropiados que mejoren el ambiente de trabajo. Los trabajadores de la enfermería tienen un rol fundamental en ayudar a los administradores de la organización a construir un ambiente de trabajo más saludable.
Key words: Nursing. Noise. Occupational health. Mental health.
Palabras clave: Atención dirigida al paciente. Diálisis Renal. Atención de enfermería.

\footnotetext{
'Professor Adjunto do Departamento de Enfermagem Médico-Cirúrgico da FENF/UERJ. Doutor em Enfermagem pela EEAN/UFRJ. Especialista em Álcool e Drogas. EERP/USP. Brasil. E-mail: eliasbo@tutopia.com.br ${ }^{2}$ Doutora em Enfermagem. Professora Adjunta do Departamento de Enfermagem Fundamental da Escola de Enfermagem Anna Nery da UFRJ. Pesquisadora do Núcleo de Pesquisa Enfermagem e a Saúde do Trabalhador da Escola de Enfermagem Anna Nery da UFRJ. Brasil. E-mail: marcialis@terra.com.br
} 


\section{INTRODUCÃO}

Nas instituições hospitalares, o Centro de Terapia Intensiva (CTI) é um dos espaços onde existe maior concentração de tecnologias diagnósticas e terapêuticas, que possibilitam às equipes de enfermagem, medicina e fisioterapia, intervir prontamente junto aos pacientes. Aparelhos como multiparâmetros, ventiladores, bombas infusoras e oxímetros com alarmes visuais e sonoros são recursos imprescindíveis para o processo de trabalho, pois alertam sobre as alterações clínicas do paciente e de mau funcionamento dos próprios aparelhos. No entanto, são fontes de ruído contínuas que, em conjunção com as de saídas de ar comprimido, oxigênio, aspiradores, computadores, telefones, manipulação de objetos, diálogo dos profissionais de saúde entre si e com os pacientes, afetam a saúde da equipe.

Estudo realizado no Hospital São Paulo (SP) ${ }^{1}$ demonstrou que o nível de ruído encontrado no CTI estava acima do recomendado pela literatura nos períodos diurno e noturno. Foi constatado que o nível de pressão sonora equivalente (Leq) apresentou média de 65,36 decibéis da escala do ouvido humano $(\mathrm{dB} A)$, variando de 62,9 a 69,3 dB(A). Durante o período diurno, a média do Leq foi de $65,23 \mathrm{~dB}(\mathrm{~A})$ e para o período noturno, 63,89 dB(A). 0 LFMax encontrado foi de 108,4 dB(A), e o LFMin, de $40 \mathrm{~dB}(\mathrm{~A})^{1}$.

Tais resultados contrariam as normas estabelecidas pela Associação Brasileira de Normas Técnicas, que recomendam 35 a $45 \mathrm{~dB}(\mathrm{~A})$ como níveis aceitáveis para diferentes ambientes hospitalares².

Portanto, o estudo coloca em evidência que os níveis de ruído no CTI, quando ultrapassados os limites preconizados, podem afetar a acuidade auditiva e demais órgãos, causando cansaço, irritação e estresse à equipe. Tais agravos à saúde dos trabalhadores de enfermagem repercutem no processo de trabalho, por acarretar lapsos de memória e maior esforço mental na realização das tarefas, expondo o grupo a riscos de acidentes e de erros na execução das tarefas 3 .

No CTI, a dinâmica de trabalho e as exigências das tarefas frequentemente conduzem os profissionais de enfermagem a vivenciar situações estressantes decorrentes do ambiente ruidoso, dos conflitos intra e interdisciplinar e da precariedade das condições de trabalho. Portanto, é imprescindível atentarmos para os riscos aos quais os profissionais de enfermagem estão expostos com vistas à melhoria da qualidade do cuidado que prestam à clientela e à sua própria saúde 4 .

0 controle do ruído em hospitais é considerado uma prioridade, devendo ser realizados estudos que avaliem a excessiva exposição a que estão sujeitos a equipe e os pacientes em CTI, a fim de prevenir a poluição sonora e promover medidas que torne mais satisfatória a permanência neste ambiente ${ }^{5}$.

A partir dessas questões, o objetivo deste artigo é discutir as estratégias coletivas de defesa elaboradas pelos trabalhadores de enfermagem decorrentes da exposição ao ruído no CTI.

\section{SUPORTE TEÓRICO}

0 trabalho é essencial ao homem, pois é fonte de prazer e pode ser uma das razões pelas quais possui tanta importância na vida do indivíduo. 0 trabalho faz com que o trabalhador não perca o desejo de permanecer produzindo, além de ter, nessa atividade, a oportunidade de realização e de identidade para construir-se como sujeito psicológico e social ${ }^{6}$. No entanto, diante de uma organização de trabalho pouco flexível, cujo espaço de liberdade entre o trabalho prescrito e o real é exíguo ou inexistente, instala-se o sofrimento, referido como um campo de investigação cujos sujeitos, apesar das pressões da organização do trabalho, conseguem evitar a doença, a loucura. Campo de normalidade que não exclui o sofrimento, não exclui o prazer e não se trata, aqui, de doença mental'.

Assim, o trabalho pode ser, ao mesmo tempo, fonte de prazer e de sofrimento, implicando uma contradição, que é guiada por um movimento de luta do trabalhador para a busca constante de prazer e evitação do sofrimento, com a finalidade de manter o seu equilíbrio psíquico. Essa dinâmica é responsável pela saúde mental, significando que não é a simples existência do prazer ou sofrimento os indicadores de saúde, mas a diversidade de estratégias que podem ser utilizadas pelos trabalhadores para enfrentar as situações geradoras de sofrimento ${ }^{6}$.

Uma das formas de enfrentamento do sofrimento é a utilização das estratégias defensivas, definidas como mecanismos utilizados pelos trabalhadores para negar ou minimizar a percepção da realidade que faz sofrer. Tais defesas dependem de condições externas e se sustentam no consenso de um grupo específico de trabalhadores ${ }^{8}$.

Assim, as estratégias de defesa emergem em contexto laboral cuja carga de trabalho caracteriza-se por situações desgastantes e determinantes de sofrimento vividas ininterruptamente pelos trabalhadores de enfermagem como a atenção constante; a supervisão estrita (controle, pouca autonomia e criatividade e não-participação na tomada de decisões); o ritmo acelerado de trabalho; o trabalho parcelado, monótono e repetitivo; comunicação dificultada; fadiga; tensão; estresse; insatisfação ${ }^{9}$

As cargas de trabalho, ou seja, elementos constituintes do processo laboral, exercem influência na equipe, gerando tentativas de adaptação, o que se observa quando as estratégias defensivas não conseguem neutralizar o sofrimento residual, isto é, quando a interação dinâmica das cargas de trabalho no processo biopsíquico humano é caracterizada por transformações negativas ou de sofrimento ${ }^{10}$

Em determinadas condições laborais, a organização do trabalho pode ser a origem psíquica negativa (fatigante), devido às excitações provenientes do exterior (de origem psicossensorial) ou do interior (excitações instintivas ou pulsionais). Quando o trabalhador consegue extravasar a carga psíquica através de mecanismos como fuga, crise de raiva e 
atuação agressiva, oferece uma gama de descargas que proporcionam o relaxamento. Na impossibilidade de descarga pela via mental ou motora, a carga psíquica não pode ser descarregada senão pela via do sistema nervoso autônomo e pelo desordenamento das funções somáticas. É a via visceral que estará atuando no processo de somatização com as suas consequências para a saúde, como úlcera gástrica, problemas dermatológicos, hipertensão e outros ${ }^{7}$.

Portanto, se o sofrimento não se faz acompanhar de descompensação psicopatológica, ou seja, de uma ruptura do equilibrio psíquico que se manifesta pela eclosão de uma doença mental, é porque contra ele existem defesas construídas e empregadas pelos trabalhadores coletivamente ${ }^{8}$.

\section{METODOLÓGIA}

Trata-se de um estudo de caráter descritivo com abordagem qualitativa, que permite desvelar processos sociais ainda pouco conhecidos, grupos particulares e expectativas sociais em alto grau de complexidade ${ }^{11}$.

0 projeto foi aprovado pelo Comitê de Ética em Pesquisa do Hospital Universitário Antônio Pedro da Universidade Federal Fluminense e protocolado no Comitê Nacional de Ética em Pesquisa com o número 27/03. Em atendimento à Resolução 196/96, após a assinatura do Termo de Consentimento Livre e Esclarecido, participaram do estudo 25 sujeitos, sendo 7 enfermeiros, 14 técnicos de enfermagem e 4 auxiliares de enfermagem de um CTI de um hospital universitário do município de Niterói (RJ). Os critérios de inclusão dos sujeitos no estudo foram: ser do quadro efetivo da Universidade e atuar no CTI há um ano.

Informou-se aos sujeitos que a participação seria voluntária e que eles teriam o direito de se retirar da pesquisa em qualquer fase. Garantiu-se o sigilo dos dados fornecidos e ratificou-se que os resultados do estudo seriam apresentados em eventos $\mathrm{e}$ publicados em revistas científicas. A identificação dos participantes foi feita a partir das iniciais da categoria profissional (E: Enfermeiro; T: Técnico de Enfermagem e A: Auxiliar de Enfermagem), do sexo (F ou M) e do número de ordem de entrada no texto (EM1, TF2...AM25).

A coleta de dados ocorreu no primeiro semestre de 2004, mediante a técnica de entrevista semi-estruturada, que possibilitou a interação entre o pesquisador e sujeitos, favorecendo a contextualização de experiências, vivências, sentidos que contribuíram para esclarecer a problemática da investigação $0^{11}$. Como instrumento, foi utilizado um roteiro contendo, em sua primeira parte, o perfil sociodemográfico do grupo e, na segunda, 13 questões abertas relacionadas ao ambiente, às condições de trabalho e ao modo como enfrentavam o problema do ruído no ambiente de trabalho, cujas respostas foram gravadas em fita cassete.

Realizada a transcrição, a linguagem foi analisada mediante técnica de análise de conteúdo ${ }^{12}$ (análise temática), que se baseia na decodificação de um texto em diversos elementos, os quais são classificados e formam agrupamentos analógicos. Em um último momento, utilizando os critérios de representatividade, homogeneidade, reclassificação e agregação dos elementos do conjunto, chegou-se aos seguintes resultados: a caracterização dos sujeitos e as estratégias coletivas de defesa dos trabalhadores de enfermagem diante do ruído no CTI; solidariedade grupal; aceleração do ritmo de trabalho; improvisação; descontração; banalização e pausa

\section{RESULTADO E DISCUSSÃO}

\section{Caracterização do grupo}

Foram entrevistados 25 trabalhadores, sendo 14 do sexo feminino e 11 do sexo masculino, cuja faixa etária variou entre 30 e 50 anos. Em relação ao estado civil, 14 eram casados; 5 , divorciados; 4, solteiros; e 2, viúvos. Quanto ao grau de escolaridade, 15 possuíam o ensino superior; 1 , o superior incompleto; e 9, o ensino médio. A renda familiar variou de 11 a 20 salários mínimos. As religiões referidas: 18 a católica, 5 a protestante 2 a cardecista. Os locais de residência: 13 residiam no município de Niterói e São Gonçalo (RJ); 9 , no município do Rio de Janeiro; e três, no estado.

Com exceção de duas técnicas de enfermagem, que foram lotadas no CTI há dois anos, os demais relataram atuar no setor há mais de cinco anos, sendo que a maior concentração de tempo de trabalho variou entre 5 e 20 anos.

\section{As estratégias coletivas de defesa dos trabalhadores de enfermagem diante do ruído no CTI}

As estratégias coletivas de defesa elaboradas pelos trabalhadores do CTI são permeadas por um conjunto de processo mentais (cognitivos) e afetivos que envolvem a pertença do grupo, valores e crenças. Deste modo, a adesão ou apoio a determinada causa deve-se aos vínculos estabelecidos e à relação de responsabilidade entre os trabalhadores, unidos por um interesse comum. Como os trabalhadores são afetados individual e coletivamente pelo ruído, todos os esforços são empregados pelo grupo no seu enfrentamento.

As exigências do trabalho na terapia intensiva em face do ruído aumentam a carga psíquica negativa devido aos efeitos de vigilância, de esforços e de deslocamentos. Os trabalhadores vivenciam tensão, insegurança e medo de perda do controle do estado clínico dos pacientes, sendo o sofrimento constatado a partir de queixas como: cansaço, irritação, desgaste e estresse.

Agora por conta dos ruídos, quando você está numa situação que você precisa concentração e os ruídos são disparados pelo defeito do aparelho, o excesso de barulho no ambiente, isso na realidade, passa a ser um problema (EM14). 
Você não podia confiar no monitor porque ele alarmava fora do horário e isto estressava a gente porque alarmava toda hora. Étão estressante, que parece que está dentro da sua cabeça. Você não podia confiar. Você tem que sair correndo. Vocênão sabe se o aparelho esta legal ou não. Aquilo te estressava, porque você queria que o aparelho funcionasse direitinho (TM2).

Na luta contra o sofrimento, os trabalhadores elaboraram ações adaptativas ou estratégias coletivas: solidariedade grupal, aceleração do ritmo de trabalho, improvisação, descontração, banalização e pausas.

\section{Solidariedade grupal}

0 ruído tecnológico afeta de modo substancial a equipe de enfermagem que trabalha em regime de plantão, pois se mantém em um setor fechado com uma pausa oficializada durante o almoço e tem sob a sua responsabilidade os cuidados ininterruptos dos pacientes. Cabe ao enfermeiro líder do plantão a supervisão, apoio técnico de sua equipe, realização de procedimentos invasivos e de maior complexidade, sendo os técnicos de enfermagem escalados nos cuidados integrais dos pacientes.

A cada admissão no setor, a equipe de enfermagem instala todo o equipamento de suporte ventilatório e hemodinâmico, checa o funcionamento e estabelece os parâmetros de alarmes sonoro e visual. Nos casos de alta, de transferência ou de óbito, os aparelhos são desconectados do paciente e encaminhados ao auxiliar de enfermagem responsável pela assepsia e preparo para utilização em outro paciente.

A familiaridade que a equipe adquire no manuseio dos aparelhos resulta em um conhecimento pragmático, possibilitando a utilização deste saber no controle do ruído tecnológico. No entanto, como relatado nas entrevistas, sempre que um novo aparelho é colocado no setor, há uma defasagem dos conhecimentos prévios e a necessidade de treinamento. Outra situação vivenciada pelo grupo,diz respeito à visita técnica dos profissionais do serviço de apoio, imprescindível na avaliação, reparo e substituição dos aparelhos.

No enfrentamento do ruído tecnológico, os trabalhadores, a partir da solidariedade grupal, se revezam no atendimento dos pacientes, compar tilham experiências, conhecimentos e recorrem à ajuda mútua como relatado nas falas:

Eu paro o que eu estou fazendo, peço auxilio ou vou ajudar o colega pra poder estacionar aquele ruído. Quem tem possibilidade de absorver melhor um conhecimento passa para o outro. Mas sempre tem alguém que é mais tímido, não teve acesso ou ficou longe, enfim algum motivo o levou a não ter acesso àquela informação (TEF9).
Já tentei de tudo, estou completamente incapaz. Vou pedir ajuda a outra pessoa para me certificar que aquilo está com defeito; pra essa pessoa dar uma olhada e tentar de alguma maneira solucionar aquilo (EF7).

A solidariedade grupal é uma estratégia que possibilita o rearranjo da organização do trabalho congruente com os desejos dos trabalhadores ${ }^{6}$. A colaboração, os revezamentos no atendimento dos alarmes, minimiza a carga psíquica negativa (fatigante) acarretada pelo ruído, pelas inspeções e pela a repetitividade da tarefa, com ganhos para a economia psicossomática. A estratégia repercute no processo de trabalho e na saúde do grupo por tornar o ambiente de trabalho menos insalubre, diminuir o excesso de estímulo psicosenssorial, o cansaço e o risco de erros.

\section{Aceleração do ritmo de trabalho}

0 ritmo de trabalho na terapia intensiva é extenuante, principalmente no horário da manhã devido à realização de cuidados integrais e do atendimento das intercorrências clínicas dos pacientes. A equipe, por possuir apenas um técnico de enfermagem, responsável pela assistência a dois pacientes, requer 0 apoio grupal para atender as exigências da tarefa.

0 ruído tecnológico prejudica a realização do trabalho por interferir na concentração, obrigando os trabalhadores a interromperem o trabalho para atender ao alarme e/ou outros ruídos originados de escapamentos nas conexões, aquecimento e alteração de ritmo dos respiradores. A interrupção da tarefa, dispersa, afeta o ritmo de trabalho e provoca maior esforço físico e mental nos trabalhadores.

Para terminarem a atividade e se afastarem do excesso de ruídos do posto de trabalho, mesmo que temporariamente, iniciam uma corrida contra o tempo. Os trabalhadores adotam um comportamento que denuncia uma tensão, pois falam alto, realizam movimentos rápidos e arrastam objetos sem o devido cuidado como uma maneira de extravasar a carga psíquica negativa.

Porque além do trabalho, se você está fazendo alguma coisa, você tem que ver o que está acontecendo. Vocêtem que parar o que estáfazendo pra correr atrás do ruído, pra ver o que está acontecendo com o paciente. Então eu acho que é muito desgastante também (EF23).

Talvez você esteja tão irritado com a situação, você está tão estressado, que você quer fazer aquilo da forma o mais rápido possível pra ficar livre um pouco do barulho, e, com isso, nem sempre a pressa está ligada à perfeição. Quer dizer, às vezes você está querendo fazer um determinado procedimento correndo e acaba não fazendo de forma correta (TEM3). 
A aceleração do ritmo de trabalho pelo grupo como estratégia de defesa possibilita a descarga psíquica através da utilização da via motora. No entanto, a exposição prolongada ao ruído, tendo o trabalhador que se adaptar às demandas em termos de vigilância, de intervenções e de deslocamentos, pode levar à exaustão psicofísica e expor o grupo aos acidentes de trabalho ${ }^{13}$.

\section{Improvisação}

Para os trabalhadores de enfermagem, os ruídos relacionados aos aparelhos de suporte hemodinâmico e ventilatório são os mais perturbadores por estarem relacionados a falhas técnicas dos aparelhos, à falta de manutenção e aos eletrodos que se desprendem dos pacientes. Tais problemas interferem no sistema de monitoramento, que não deve alterar a rotina de cuidados nem dificultar a abordagem emergencial do paciente ${ }^{14}$.

Diante de falhas técnicas e/ou de mau funcionamento de aparelhos que alarmam insistentemente, os trabalhadores necessitam do suporte do serviço técnico, responsável pela manutenção ou substituição deles. Como o atendimento da solicitação envolve instâncias organizacionais e os aparelhos não podem ser desconectados do paciente, os trabalhadores, na tentativa de solucionar os problemas, recorrem à improvisação.

Você faz os famosos gatilhos, adapta isso, adapta aquilo. Resolve de um jeito, tenta resolver. Mas se isso estiver ruim, as outras coisas não vão funcionar. Acho que isso deve ser levado em conta também (TEF19).

Ou às vezes até um canibalismo, que a gente faz. Adapta um circuito de um aparelho no outro. Pode acontecer do aparelho não ficar bem ajustado e aí ele alarma, alarma, alarma, alarma. Na hora que acontece de desconectar... Muitas vezes vocêpensa que ele esta alarmando normalmente e não é! Realmente é uma coisa séria. É um mal necessário, é perigoso, mas a gente precisa dos alarmes (AEF20).

Nessas circunstâncias, o sofrimento advém de um conflito vivido pelo trabalhador por saber que, apesar das intervenções, o seu poder decisório é mínimo ou inexistente. A prática do quebra-galho autoriza o trabalhador a adaptar intuitivamente a organização do trabalho às necessidades de seu organismo e suas aptidões fisiológicas e exige uma atividade intelectual e cognitiva. No entanto, os trabalhadores esbarram nos riscos técnicos, pois o conjunto de macetes assim compartilhado permanece pragmático, fruto da experiência e observação, incompleto e pouco tranquilizador?.

\section{Descontração}

As condições adversas de trabalho relacionadas ao ambiente do CTI com seus ruídos característicos, a precariedade de recursos humanos e materiais, a especificidade do trabalho, que exige intervenções complexas, e as atitudes conflitantes intra e intergrupais geram nos trabalhadores de enfermagem estresse e suas consequências para a saúde 4 .

A carga psíquica negativa gerada pela exposição contínua dos trabalhadores a essas situações, entre elas o ruído, que entra como mais um agravante, provoca insatisfação e ansiedade, administradas pelo grupo através da estratégia de descontração por meio de brincadeiras e de conversas nos encontros, na realização das atividades e nas pausas.

Os próprios colegas se alegram com os outros $e$ aumentam o barulho. Um local que precisa de tranquilidade, e, às vezes, nós mesmos não colaborávamos com isso, porque a gente já estava estressada e falava alto sem perceber (TEF2).

Mas eu acho que as conversas, as brincadeiras pra essas pessoas que falavam alto no setor, eu acho que é uma maneira que elas têm pra poder suportar aquelas doze horas ali no setor fechado, com aquela tensão toda, acho que é uma maneira de elas suportarem aquilo ali (EF7).

A familiaridade, o saber prático advindo da experiência e o controle sobre o processo de trabalho propiciam aos trabalhadores um espaço de liberdade, que permite ao grupo dar vazão à tensão avinda da pressão laboral, na busca do equilíbrio e do bem-estar no trabalho. Se o trabalho favorece esse livre funcionamento, engendrado pelo próprio trabalhador, ele será fator de equilíbrio; se ele se opõe, será fator de sofrimento e de doença ${ }^{15}$.

\section{Banalização}

A banalização do ruído dos aparelhos conectados aos pacientes foi uma estratégia de defesa referida pelos trabalhadores, a partir de atitudes de indiferença e de nãointervenção que culminam no desvencilhar de responsabilidades. Ao adotar este comportamento, os trabalhadores transferem a responsabilidade de resolver 0 problema para os demais, não sendo evocada a gravidade do paciente ou o mau funcionamento do aparelho.

Pessoas que ouvem o mesmo som e que têm atitudes diferentes diante desse som. Uns rapidamente levantam e vão ver o que está acontecendo, outros investigam o paciente como um todo. Outros não fazem simplesmente nada. Às vezes nem se levantam pra ver o que está acontecendo. Se limitam à distância, a olhar o que está acontecendo, e não mais do que isso (EM24). 
Então algumas pessoas, eu acho que já se acostumaram com o ruído. Aquilo não é possivel! Ou se acostumaram ou entra no caso da preguiça; do descaso. Porque eu acho que não lidam muito bem. Eu acho que o pessoal, como eles falam, acabam não percebendo mais. Acho que aquele ruído passa a ser natural (EM18).

A estratégia assumida por alguns membros do grupo pode gerar conflitos, minar a coesão interna e propiciar o isolamento. Não se trata de atender ou não um alarme, mas atentar para o significado que se encontra subjacente a ele, o que exige intervenções como avaliar o paciente ou identificar as possíveis falhas técnicas dos aparelhos que possam implicar riscos para o paciente e para a própria equipe.

A forma como o trabalho é organizado permite a realização de atividades com conteúdos significativos ou não, bem como influencia o sentido particular que assume para cada trabalhador. Quanto à falta de significação do trabalho, ela é atribuída à divisão do trabalho em tarefas mínimas, sendo a responsabilidade, a solução de problemas e as tomadas de decisões atribuições da gerência ${ }^{16}$.

\section{Pausas}

No CTI, como relatado pelo grupo, existe um espaço destinado ao descanso da enfermagem, onde os trabalhadores se encontram, lancham e conseguem um afastamento temporário do nível de ruído do posto de trabalho. Como a sala está localizada dentro do CTI, é impossível ficar indiferente aos ruídos dos aparelhos. Uma das soluções encontradas pelo grupo para se afastar dos ruídos foi o revezamento, principalmente no período da tarde, quando diminui o ritmo de trabalho.

No revezamento, dois trabalhadores permanecem no posto, mantêm a vigilância e atendem às intercorrências, e dois usufruem da pausa por alguns minutos, dentro ou fora do setor. Por ser um acordo grupal, a pausa não é oficializada, e há dias em que, em virtude das intercorrências diversas, não tem como recorrer a essa estratégia.

0 afastamento dos trabalhadores do posto, mesmo que por um cur to espaço de tempo, é uma estratégia eficaz por aliviar a tensão acarretada pelo estado de alerta permanente.

Agora a gente observa, lidando com várias equipes, com várias pessoas com as quais a gente acaba trabalhando no decorrer de vários anos, que as pessoas, elas muitas vezes precisam dar uma saída, de respirar, vamos dizer assim. Elas saem, nem que seja pra fumar um cigarro, dar uma relaxada. (EM18)

Se for num dia de pico eu geralmente saio, dou uma saída de 15 minutos, respiro num local mais tranquilo ou num setor mais tranquilo, onde tenha uma pessoa que você possa conversar banalidades (TF8).
Ao compartilharem as responsabilidades e adaptarem a organização às suas necessidades, os trabalhadores vivenciam um sentimento de autonomia, de estarem gerenciando o próprio trabalho. Por ser um acordo grupal, há ganhos para o processo de trabalho e para a economia psicossomática, o que gera satisfação e a motivação no trabalho. Esta adaptação espontânea do trabalho ao homem corresponde à procura, à descoberta, ao emprego e à experimentação de um compromisso entre os desejos e a realidade. Um trabalho livremente escolhido, ou livremente organizado, oferece, geralmente, vias de descarga mais adaptadas às necessidades do trabalhador ${ }^{15}$.

\section{CONSIDERAÇÕES FINAIS}

0 ruído na terapia intensiva, por se encontrar em níveis acima do recomendado pelas Normas Regulamentares (NR), é um agente físico capaz de afetar a saúde do trabalhador de enfermagem, devido a um conjunto de variáveis relacionadas à fonte (aparato tecnológico), à proximidade e ao tempo de exposição. Como o grupo tem sob a sua responsabilidade o controle dos parâmetros ventilatórios e hemodinâmicos dos pacientes conectados aos aparelhos, as exigências da tarefa requerem estado de alerta permanente e inspeções periódicas de todo o sistema, principalmente quando os alarmes são disparados.

Por se manter no posto de trabalho, trabalhar em regime de plantão e ter apenas uma pausa oficializada, a equipe de enfermagem é afetada de maneira substancial pelo ruído, devido à exposição contínua e ao excesso de estimulação psicossensorial (visual e sonoro) e pelas exigências da tarefa. Fatores que contribuem com o aumento da carga psíquica negativa (fatigante) constatada a partir das queixas, como cansaço, irritação, desgaste e estresse, evidenciaram 0 sofrimento no trabalho.

Como o trabalho na terapia intensiva também proporciona prazer, os trabalhadores, diante da exposição ao ruído, mobilizam mecanismos adaptativos ou estratégias coletivas de defesa para não desistirem do trabalho e nem adoecerem física e psicologicamente. São estratégias que, ao serem elaboradas coletivamente, situam o trabalhador como sujeito do processo de trabalho. Assim, a despeito das pressões da organização do trabalho, o grupo recorre ao saber prático, utilizando-se da margem de liberdade entre o trabalho prescrito e o real, para intervir no contexto de trabalho de modo a tornálo congruente com os seus desejos.

Por outro lado, as ações adaptativas elaboradas pelos trabalhadores diante do ruído ocultam as exigências físicas e psicológicas do trabalho que fazem sofrer, podendo resvalar para a alienação no trabalho. Ao se alienarem, os trabalhadores poderão não mais se engajar pela luta em prol de mudanças efetivas em termos do monitoramento e controle do ruído laboral que revertam em saúde e bem-estar para o grupo.

Quanto à ação preventiva pela organização, cabe ratificar a importância do monitoramento das fontes de ruído, da manutenção preventiva dos aparelhos, do controle do fluxo de pessoas no setor e da qualificação profissional para lidar com as novas tecnologias. 


\section{REFERÊNCIAS}

1. Pereira RP, Toledo RN, Amaral JLG, Guilherme A. Qualificação e quantificação da exposição sonora ambiental em uma unidade de terapia intensiva. [on-line]. Rev Bras Otorrinol 2003; 69 (6): 766 71.

2. Associação Brasileira de Normas Técnicas-NBR 10151. Avaliação do ruído em áreas habitadas visando o confor to acústico da comunidade. Rio de Janeiro (RJ); 2000.

3. Oliveira EB, Lisboa MTL. The impact of noise for the nursing workers health and the work process. Online Brazilian of Nursing [on-line] 2007; 6 (3): 1237- 266. Available from:http://www.uff.br/ objnursing/index.php/nursing/article/view/j.1676-

4285.2007.1237/266.

4. Santos JM, Oliveira EB, Moreira AC. Estresse, fator de risco para a saúde do enfermeiro em Centro de Terapia Intensiva. Rev Enferm UERJ 2006; 14 (4): 580-85.

5. Otênio MH, Cremer E, Claro EMT. Intensidade de ruído em hospital de 222 leitos na $18^{\text {a }}$ Regional de Saúde - PR [on-line]. Rev Bras Otorrinolaringol 2007; 73 (2): 3499-250. Disponível em: buscatextual.cnpq.br/buscatextual/visualizacv.jsp?id=K4707929T3 $66 \mathrm{k}$

6. Mendes AM, Borges LO, Ferreira MC. Trabalho em transição: saúde em risco. Brasília (DF): Ed. Universidade de Brasília; 2002.

7. Dejours C. A banalização da injustiça social. Tradução de Luiz Alberto Monjardim. $4^{\mathrm{a}}$ ed. Rio de Janeiro (RJ): FGV; 2001.
8. Dejours C. A psicodinâmica do trabalho: contribuições da escola Djouriana à análise da relação prazer, sofrimento e trabalho. São Paulo (SP): Atlas; 1994.

9. Haddad MC. Proposta de implementação de um programa interdisciplinar de apoio ao trabalhador de enfermagem. Rev Esc Enferm USP 1998 dez; 32 (4): 307-13.

10. Souza NVDO, Lisboa MTL. Compreendendo as estratégias coletivas de defesa das trabalhadoras de enfermagem na prática hospitalar. Esc Anna Nery Rev Enferm 2002; 6 (3): 425 - 35.

11. Minayo MC. 0 desafio do conhecimento: pesquisa qualitativa em saúde. $5^{\text {a }}$ ed. Rio de Janeiro (RJ): ABRASCO; 2001.

12. Bardin L. Análise de conteúdo. Lisboa (PO): Ed 70; 1977.

13. Nishide VM, Benatti MCC, Alexandre NMC. Ocorrência de acidentes do trabalho em uma Unidade de Terapia Intensiva. Rev Latino-am Enfermagem 2004; 12 (2): 204-13.

14. Luz M. Monitorização hemodinâmica não-invasiva In: Silva LD, organizador. Cuidados ao paciente crítico: fundamentos para a enfermagem. $2^{\mathrm{a}}$ ed. Rio de Janeiro (RJ): Cultura Médica; 2003.

15. Dejours C, Dessors D, Desriaux F. Por um trabalho, fator de equilíbrio. Rev Administr Empr 1993; 33 (3): 98-104.

16. Palácios M. A saúde mental de quem trabalha em saúde: o caso de um hospital geral no município do Rio de Janeiro. Cadernos IPUB 1997; 2 (n esp): $43-55$. 